\title{
Professor - intensificação do trabalho e o uso da voz
}

\section{Teacher - work intensification and use of voice}

\author{
Delmira de Fraga e Karmann', Selma Lancman²
}

\section{RESUMO}

Objetivo: Identificar, por meio de relatos de professores do Ensino Fundamental, condições que interferem, direta ou indiretamente, no seu desempenho vocal e nas circunstâncias do seu trabalho. Métodos: Pesquisa realizada com oito professoras da rede municipal de ensino de São Paulo, em cinco sessões de grupo focal. Os temas disparadores foram: o que é ser professor/a na atualidade, violência e saúde dos professores. As sessões foram gravadas e transcritas, os conteúdos analisados e organizados em categorias e subcategorias, dentro de quatro tópicos: voz, trabalho, violência e inclusão escolar. Resultados: Os professores necessitam falar muito para garantir atenção e resultado do trabalho; trabalhar conteúdos comportamentais e atitudinais; resolver e negociar conflitos; administrar a violência na sala de aula; controlar situações e acalmar as crianças. Há uso intenso e contínuo da voz para outras situações, além da aula. "Gritar" e "falar alto" foram associados a competir com o ruído interno e externo à sala de aula, à quantidade de alunos e a exercer controle imediato sobre imprevisibilidades. A desorganização da rotina (interrupções constantes) sobrecarrega os professores, física e mentalmente. As crianças do programa de inclusão escolar acentuam esses problemas. Conclusão: A nova regulação das políticas educacionais reestruturou a atividade docente, sobrecarregando e intensificando seu trabalho, precarizando condições laborais e interferindo na sua organização. O professor é solicitado cotidianamente ao uso intenso da voz para resolver situações distintas - além de ministrar a aula - sem possibilidade de descanso e em condições adversas, resultando no adoecimento do corpo e da mente.

Descritores: Voz, Distúrbios da voz; Docentes; Educação; Saúde do trabalhador

\begin{abstract}
Purpose: Identify, using elementary school teacher's reports, which conditions could affect, directly or indirectly, the vocal performance of these professionals, taking in account their work conditions. Methods: Research conducted with eight female teachers from São Paulo city public education system that participate in a focal group during five sessions. Triggers themes like the role of the teacher at the present time, violence and the teacher's health were used. Sessions were recorded and transcribed. Content was analyzed and organized in categories and subcategories into four main themes: voice, work, violence and the inclusion of students with disabilities. Results: Teachers reported the need to speak frequently in order to: guarantee attention and results from work; elaborate behavioral and attitudinal issues; solve and negotiate daily conflicts; manage violence in classroom; control situations; calm down the students. Apart from the class itself, there is intense and continuous voice use. Screaming and loud talking were related to the need to overcome internal and external noises; the number of students; exert immediate control over an eventuality. The disorganization of the routine (constant interruptions) overloads teachers both mentally and physically. The inclusion of students with disabilities contributes to this problem. Conclusion: New regulation of the educational policies restructured the teacher's labor, leading to an overload and hardening of the classroom work, undermining working conditions and interfering in your organization. Teacher is asked daily to an intense voice use to solve various situations - in addition to delivering the lesson - without possibility of resting and in adverse conditions that cause body and mind illness.
\end{abstract}

Keywords: Voice; Voice disorders; Faculty; Education; Occupational health

Trabalho realizado no Hospital do Servidor Público Municipal de São Paulo - HSPM - São Paulo (SP), Brasil.

(1) Hospital do Servidor Público Municipal de São Paulo - HSPM - São Paulo (SP), Brasil.

(2) Departamento de Fisioterapia, Fonoaudiologia e Terapia Ocupacional, Faculdade de Medicina, Universidade de São Paulo - USP - São Paulo (SP), Brasil. Conflito de interesses: Não

Contribuição dos autores: $D F K$ pesquisador principal, elaboração da pesquisa, elaboração do cronograma, levantamento da literatura, coleta e análise dos dados, redação do artigo, submissão e trâmites do artigo; $S L$ orientadora, elaboração da pesquisa, elaboração do cronograma, análise dos dados, aprovação da versão final. Endereço para correspondência: Delmira de Fraga e Karmann. R. Comendador Elias Assi, 682/4, Caxingui, São Paulo (SP), Brasil, CEP: 05561-000.

E-mail: delmira.karnna@terra.com.br

Recebido em: 4/2/2013; Aceito em: 21/8/2013 


\section{INTRODUÇÃO}

Os professores do município de São Paulo são atendidos, em grupo, pela Seção de Fonoaudiologia do Hospital do Servidor Público Municipal de São Paulo, há 20 anos. Do atendimento em grupo $^{(1)}$, foi possível compreender outras dimensões do trabalho dos professores, como fatores relativos ao ambiente e à organização do trabalho, interferindo na voz. Os seminários promovidos pelo GT-Voz da PUC-SP, junto a outras instituições que discutiam o atendimento a pessoas com distúrbios de voz, instituíram-se como o fórum para debate dessas questões. Nesses encontros, houve o reconhecimento de alterações vocais decorrentes do uso profissional da voz, sob certas condições do ambiente do trabalho ${ }^{(2)}$. Em decorrência, foi realizada uma pesquisa com os professores do município de São Paulo, por meio de questionário, a fim de conhecer as condições de sua produção vocal. A análise dos resultados indicou fatores ambientais que podiam contribuir para a ocorrência do distúrbio de voz, como a presença de riscos químicos, ergonômicos, físicos e de acidente ${ }^{(3)}$. Alguns dados se destacaram: a média de 35 a 40 alunos por sala de aula; $60 \%$ dos pesquisados tinham, ou haviam tido, distúrbio de voz de início insidioso e apenas $38,6 \%$ procuraram se tratar; o ambiente físico das escolas foi considerado local ruidoso, empoeirado, com acústica insatisfatória, de tamanho inadequado, com limpeza precária e realizada com produtos irritativos. Com relação à saúde geral, relataram queixas de dor de cabeça, ansiedade, problemas na coluna e alergias, dentre outras. Como sintomas da alteração vocal, esses professores apresentaram garganta seca, rouquidão, cansaço ao falar, pigarro e ardor na garganta. Foram significativos na análise estatística, entre outros dados, falar excessivamente e o hábito de gritar em sala de aula. Em relação ao ambiente de trabalho, fizeram referência ao ritmo de trabalho e ambientes estressantes; falta de tempo para desenvolver todas as atividades na escola, obrigando-os a levar tarefas para casa; necessidade de carregar peso com frequência e realização de esforço físico intenso. Em relação às condições do trabalho, a grande maioria dos professores $(80,9 \%)$ queixou-se de fatores que interferem na sua vida pessoal, como indisciplina, pichações, brigas, depredações e agressões.

Foram desenvolvidos vários estudos epidemiológicos nacionais que evidenciaram a existência de associação entre queixas de saúde e condições e organização do trabalho ${ }^{(4-7)}$, especialmente em escolas de ensino infantil e fundamental ${ }^{(8)}$. Nos professores do município de São Paulo, os distúrbios psíquicos e vocais são as principais causas de afastamento do trabalho ${ }^{(9)}$. O professor tem sido bastante estudado, tanto pela Fonoaudiologia quanto por outras áreas ${ }^{(10,11)}$, mas mesmo assim continuam adoecendo, encontrando dificuldades em se afastar de seu local de trabalho para se tratar e voltando a adoecer após o tratamento, sugerindo que o distúrbio de voz do professor ainda não foi suficientemente esclarecido.

O objetivo desta pesquisa foi identificar, por meio de relatos de professores do Ensino Fundamental, quais as condições que interferem, direta ou indiretamente, no desempenho vocal de professores, diante das circunstâncias atuais do seu trabalho, a fim de que sejam consideradas, tanto na abordagem terapêutica, quanto na melhor compreensão do distúrbio de voz relacionado ao trabalho.

\section{MÉTODOS}

Este artigo tem foco nas condições do uso da voz no ambiente escolar e o trabalho do professor. A pesquisa foi submetida e aprovada pelo Comitê de Ética em Pesquisa da Faculdade de Medicina da Universidade de São Paulo (USP) (parecer $n^{\circ}$ 181/10) e pelo Comitê de Ética em Pesquisa do Hospital do Servidor Público Municipal de São Paulo (parecer no 193/2010).

Foram selecionados professores com distúrbio de voz da rede municipal de ensino de São Paulo, que procuravam espontaneamente à Clínica de Otorrinolaringologia do Hospital do Servidor Público Municipal de São Paulo (HSPM) e eram encaminhados para avaliação na Seção de Fonoaudiologia. Foram critérios de inclusão: ter realizado avaliação otorrinolaringológica e fonoaudiológica, ministrar aula para o Ensino Fundamental na prefeitura de São Paulo, não ter sido submetido à terapia de voz naquele hospital, concordar em participar da pesquisa por meio da assinatura do Termo de Consentimento Livre e Esclarecido (TCLE). Foram excluídos os professores que estavam readaptados e aposentados. Não houve desistência por parte dos que concordaram em participar e todos foram orientados quanto ao objetivo, o caráter voluntário e a garantia de sigilo da pesquisa.

O grupo foi formado por oito professoras que lecionavam no Ensino Fundamental, com média de idade de 42 anos e 6 meses, idade mínima de 32 anos e máxima de 49 anos, que trabalhavam de oito a 26 anos em sala de aula e, na prefeitura, de seis a 24 anos. Seis delas trabalhavam em dois períodos e duas em apenas um. Cinco haviam tirado licença médica por distúrbio de voz até o momento da pesquisa e três ainda não haviam tirado nenhuma licença médica.

O grupo formado participou de cinco sessões de grupo focal, para realização de pesquisa qualitativa exploratória, em datas previamente combinadas, no próprio hospital, em local protegido de ruídos, com a participação do moderador/ pesquisador e um observador. Cada sessão de grupo focal teve duração aproximada de uma hora e meia ${ }^{(12)}$.

Os temas e questões que nortearam as cinco sessões dos grupos focais foram resumidos e apresentados no Quadro 1.

As sessões foram gravadas e transcritas. Com base nos dados gerados nos grupos focais, foi criada uma codificação de categorias, identificando os temas gerais e as subcategorias. Esses temas gerais se diferenciam das subcategorias por serem questões "autônomas". As subcategorias - temas mais específicos - tratam de aspectos particulares relacionados a 
Quadro 1. Resumo dos temas e material de cada sessão de grupo focal

\begin{tabular}{|c|c|c|}
\hline Temas & Finalidade & Material \\
\hline O que é ser professor? & $\begin{array}{l}\text { Criar uma dinâmica grupal; } \\
\text { Discutir o sentido do trabalho. }\end{array}$ & $\begin{array}{l}\text { Solicitação para que respondessem: } \\
1^{\circ} \text { Porque você escolheu ser professora? Com o } \\
\text { curso dos debates: } \\
2^{\circ} \text { Como é ser professora hoje? Depois de algumas } \\
\text { colocações surgiu a necessidade de perguntar: } \\
3^{\circ} \text { O que tem de bom na escola? }\end{array}$ \\
\hline $\begin{array}{l}\text { A violência entre os alunos afeta seu } \\
\text { trabalho? } \\
\text { OBS: temas foram surgindo esponta- } \\
\text { neamente e se antecipando ou entrelaçando } \\
\text { no correr das atividades de cada grupo. }\end{array}$ & $\begin{array}{l}\text { Conhecer o que elas descrevem como } \\
\text { violência. } \\
\text { Levantar como reagem a essas situações, } \\
\text { quais são os sentimentos e como interferem } \\
\text { no trabalho, }\end{array}$ & $\begin{array}{l}\text { Solicitação para que respondessem: } \\
\text { Se tem violência, o que é para vocês violência na } \\
\text { escola? } \\
\text { Violência dirigida ao professor, tem? } \\
\text { Como é trabalhar nessas condições? } \\
\text { Comentar: O professor tem vergonha de relatar a } \\
\text { violência que sofre. } \\
\text { Foi pedido que refletissem, para o próximo } \\
\text { encontro, qual a reação quando algum professor } \\
\text { sofre uma agressão. }\end{array}$ \\
\hline $\begin{array}{l}\text { Como refletem, no professor, as atitudes } \\
\text { agressivas dos alunos em relação a ele? }\end{array}$ & $\begin{array}{l}\text { Levantar como reagem a essas situações, } \\
\text { quais são os sentimentos e como interferem } \\
\text { no trabalho, }\end{array}$ & $\begin{array}{l}\text { Comentários sobre o que foi proposto na sessão } \\
\text { anterior: } \\
\text { Como repercute nos outros professores mesmo que } \\
\text { não tenham sido diretamente agredidos? }\end{array}$ \\
\hline $\begin{array}{l}\text { Se há violência entre os educadores como } \\
\text { é vivida? } \\
\text { (esta proposta foi desconsiderada por não } \\
\text { ter tido ressonância neste grupo) }\end{array}$ & $\begin{array}{l}\text { Investigar se a organização do trabalho } \\
\text { interfere na relação entre os docentes } \\
\text { (apareceu inserida em outros discursos) }\end{array}$ & $\begin{array}{l}\text { Leitura de trechos de pesquisa sobre Bullying, } \\
\text { apresentando dados para esclarecimento de tema } \\
\text { levantado por elas. }\end{array}$ \\
\hline $\begin{array}{l}\text { Percebem se há influência da violência em } \\
\text { sua saúde e em sua voz? }\end{array}$ & $\begin{array}{l}\text { Conhecer os significados atribuídos à } \\
\text { violência e sua relação com a saúde. } \\
\text { Relacionam com suas alterações de voz? }\end{array}$ & $\begin{array}{l}\text { Leitura de trechos da dissertação "Histórias que } \\
\text { fazem sentido" com relatos de professores sobre } \\
\text { o tema (material em anexo). }\end{array}$ \\
\hline
\end{tabular}

configurações mais amplas. Isso não impede que se relacionem a mais de um tema geral. É um processo iterativo, sistemático e extensivo, observando conceitos, linguagem, estrutura de sentença, polaridades ou contínuos, insights dos participantes, códigos, contradições e similaridades, dentre outros aspectos ${ }^{(12)}$.

Houve necessidade de organizar os dados em quatro temas gerais para melhor compreensão, pois os discursos foram extensos e ricos em cada uma das sessões, porém, neste artigo só usaremos dois temas gerais: Voz e $\mathrm{O}$ trabalho do professor.

\section{RESULTADOS}

As participantes desenvolveram temas relacionados à sala de aula, ao seu desempenho profissional, às condições e organização do trabalho docente, discorrendo sobre como é ser professor/a hoje em dia, abordando as relações com os alunos, com os pais e a direção das escolas, seus sentimentos, medos, angústias, dificuldades, dentre outros, todos em relação à voz, de forma a nos permitir olhar o mundo de seus pontos de vista.

Embora os temas disparadores tenham sido sobre a violência no ambiente escolar, quando foi solicitado que comentassem se havia violência e o que consideravam violência em seu contexto de trabalho, surgiram, espontaneamente, questões relativas ao trabalho e à saúde física - incluindo a voz - e mental.

\section{A) Voz}

1) Como instrumento de trabalho

(P6) [...] Às vezes, você grita o dia inteiro e quando termina a aula você fez alguma coisa. Às vezes, sai exausta com dor de cabeça, mas valeu. E quando você não consegue?

2) Condições adversas: sobrecarga e desgaste

2.1. Necessidade de falar excessivamente, gritar, outros recursos:

(P3) [...] um dos maiores problemas que nós temos é o número de alunos, porque o dia que chove ou que tem algum evento que você vê que falta bastante, que vêm $24,26 \ldots$ nossa, o dia que tem vinte e poucos... eu não preciso gritar, eu não preciso falar alto, sabe? Eu consigo falar: pessoal... turma. Eles param, eles olham. Agora, o dia que está 35, 36... (voz desanimada, fraca) não tem como.

\subsection{Imprevisibilidades em sala de aula:}

(P3) Eu, às vezes, me sinto como aquele marcador de pressão que os médicos usam, [...]. De repente, está baixo e de repente "pá", vai lá em cima, por que? De repente, a sala está tranquila, aí... de repente, do nada... você é obrigada a explodir, a gritar, dar um murro na mesa. Nós não estamos livres [...] de ter um problema psiquiátrico, um derrame [...]

2.3 Distúrbio de voz e impotência diante das adversidades (P6) Às vezes, você tem uma sala tão difícil, tão difícil, que 
tudo que você pensa em fazer fica pela metade, fica truncado (concordâncias: é, é, é).

3) Adoecimento

3.1. Paradoxo: trabalhar com ou sem voz:

(P2) Porque várias vezes eu trabalhei sem voz e porque eu não quero faltar... preocupada com o meu aluno. Até para eu estar vindo aqui, está sendo difícil pra mim. Pra eu achar... que eu tenho que vir aqui, será que eu não poderia cuidar de outro jeito? Eu tenho escutado muitas amigas, que são mais velhas de profissão - "Vai, não deixa de ir" [...]

3.2. Distúrbio de voz e as tensões/emoções:

(P1) O professor tem que reconhecer quando o seu termômetro está subindo, para não chegar ao ponto de agredir um aluno. Então, você está lá, o menino está perturbando, você fala "Para", "Para". Parece que quanto mais você fala para parar, mais ele te cutuca, né? Então, você tem que saber, seu termômetro vai subir? Você tem que tomar uma atitude, você vai tomar medicamento que está na sala...

3.3. Desistência de se cuidar e frustração:

(P2) Faz uns três anos que eu tenho tido problemas com a voz. Desde o ano retrasado que a minha voz... é essa. Essa voz é a voz que eu adquiri. Eu nunca fico bem. Engraçado que nem nos dias de folga. Realmente é um cansaço muito grande, é um estresse muito grande, porque nós temos muitas atribuições, às vezes, que nem são competências, mas são atribuições que chegam na nossa sala...

4) Violência

4.1. Reações emocionais e corporais à violência:

(P2) (quando um professor é agredido por aluno) [...] a gente fica indignado, a gente conversa. Acaba desabafando, mas é o medo, fica um medo intrínseco nos colegas e na pessoa que está sofrendo a violência diretamente. A indignação e o silêncio $[. .$.$] nos vemos assim... solitários, em relação a essa$ questão da violência.

\section{B) O trabalho do professor}

1) Condições do trabalho

1.1. Estrutura física, material e de recursos humanos:

(P1) [...] o professor, além de tudo isso, ainda tem que se preocupar que não tem ninguém [...] para te dar uma orientação... [...] Agora tem as crianças especiais [...] Vai procurar a coordenação, que seria aquela pessoa que vai te orientar dentro da sala de aula: "Ah, faz de conta que você não está mais ouvindo os gritos", "daqui a pouco você já internaliza isso", "você não vai mais ouvir os gritos daquela criança, não se preocupa"... você está procurando uma orientação para saber trabalhar, não para você fingir de conta que aquele aluno que tem a necessidade especial está ali, ele é uma criança, é um ser humano, ele é um aluno seu. Você fica perdida, fica sozinha para tudo isso.

1.2. Violência, condições e organização das escolas:

(P4) [...] o tempo e o espaço da escola favorecem essa violência. São muitas crianças, não dá para culpar o inspetor.
Muitos deles são readaptados, são pessoas de idade, são poucos funcionários para muita criança. Descem muitas salas ao mesmo tempo. A escola favorece isso, porque é muito barulho, as crianças não conseguem comer, um quer correr, o outro quer brincar, o tempo é curto, eles têm no máximo, depois que vão ao banheiro, 15 minutos. A fila da merenda é gigantesca, então ele não sabe se come, se brinca. Descem muitas salas, os funcionários não conseguem dar conta, o espaço não favorece e é muito barulho, eles não tem uma mesa para comerem, um senta junto, o outro passa correndo, derruba o leite, ele vai bate, porque "derrubaram tudo em cima de mim". A organização das escolas favorece a violência. Eles já sobem agitados até você acalmar tudo aquilo. Sem contar que tudo para mim é uma agressão: a sala de aula é mal iluminada, a lousa... a criança não consegue enxergar direito porque ela é horrível mesmo e aí ele grita com o fulaninho "Ô meu, senta que eu não tô enxergando". O outro acha que tem que sentar no outro lugar, porque o reflexo da luz atrapalha. Aí senta. "Você é folgado!". Aí é folgado porque sentou na minha frente... Aí já (dá um tapa no ar, como se fosse na cabeça de alguém na sua frente).

2) Organização do trabalho

2.1. Sobrecarga/intensificação do trabalho:

(P3) [...] se chega um paciente, uma pessoa no hospital, doente e aquela doença não tem cura, ou o paciente morre. Ninguém vai chegar no médico, no enfermeiro e falar "Você tem que conseguir curar, você tem que conseguir fazer ele viver". Na escola é assim: você teeem que conseguir que tenham disciplina, você teeem que conseguir dominar a sala, você teeem que conseguir alfabetizar, é assim...

2.2. Desvalorização da profissão:

(P2) [...] mas enquanto profissional, o professor não é reconhecido pela sociedade. É por isso que fazem isso com a gente, tudo isso na escola, $[\ldots]$ se pensa uma política para as pessoas portadoras de deficiência, mas não se efetiva, manda para a escola. A impressão que dá na sociedade é "ah, qualquer um vai dar aula" e não é. Exige competência, a gente precisa de formação, a gente precisa estudar.

(P6) Essa pergunta é famosa: se a gente também trabalha ou se a gente só dá aula.

2.3. Problemas de gestão da sala de aula:

(P5) [...] ele tem que dar conta de tudo, se ele não der ele é incompetente. Professor que chama a direção para resolver coisas, chama inspetor é um professor que não tem competência para gerir a sala de aula dele. [...] o professor não aguenta e põe para fora da sala, aí "já pôs prá fora da sala... olha, não consegue dar conta".

(P2) [...] Se você tem um aluno que parte para a agressão, a culpa é sua. Você que não está fazendo seu trabalho.

2.4. Relações no trabalho:

(P4) [...] (por causa de falta para tratamento) eu fui ameaçada... cheguei na secretaria e ela falou "Eu já mandei a cópia do teu ponto para a supervisão", [...]. Eu já mandei a cópia do seu ponto para a supervisão. [...] "porque você está com 
uma classe de $1^{\circ}$ ano e você está prejudicando os alunos". Porque, de novo, era uma escola muito problemática e a diretora não parava lá. Ela mandou realmente, não foi só ameaça, [...].

As expressões "falar muito" e "falar tanto" estiveram presentes recorrentemente nos discursos das professoras e foram relacionadas às atividades didáticas na convocação da atenção das crianças, ao trabalho com a parte comportamental e atitudinal dos alunos e ao controle da disciplina. Destacaram a ocorrência de resolução diária de conflitos que ocorrem na sala de aula, principalmente após os intervalos, e que tomam quinze minutos do tempo previsto de aula em negociações e acordos a serem mediados.

Na presente pesquisa, o "falar alto", "o gritar" e "o berrar" foram associados ao número de alunos em sala de aula, pois 35 a 40 alunos elevam significativamente o ruído e a indisciplina. Podemos observar que, por essas e por outras ocorrências, o tempo de aula fica reduzido. Porém, o conteúdo precisa ser garantido, expressando, por consequência, a intensificação do trabalho do professor e do uso de sua voz.

Para as participantes deste estudo, há necessidade de falar excessivamente para alcançarem sua função como educadoras. Muitas vezes, pelas situações de trabalho, sobrepõem tarefas enquanto dão a aula, controlam a disciplina, atendem algum aluno individualmente e se preocupam com as crianças do programa de inclusão escolar, indicando a intensificação do trabalho, o que pode explicar o cansaço físico, vocal e mental dos professores. Praticamente, não há repouso vocal entre as atividades.

Observou-se, neste estudo, que mesmo a manutenção da intensidade de voz mais baixa na sala de aula, tem um custo, um desgaste, pois a tentativa da professora em manter a calma, a voz pausada - para exemplificar a não violência - é muito difícil, embora uma delas tenha percebido que, em termos educacionais, obtém-se melhores resultados.

À medida que as docentes vão percebendo dificuldades com a voz, tentam se controlar, no sentido de não falar alto, não falar muito, não gritar, mas, invariavelmente, ultrapassam os limites e gritam para conter a classe. Foram unânimes em afirmar que quando têm que exercer controle imediato diante de situações críticas, o recurso é a voz com intensidade forte, ou o grito.

As repercussões no corpo e, consequentemente, na voz, de impactos advindos de situações em que chegaram ao limite e tiveram atitudes intempestivas, como jogar a cadeira na parede, foram relatadas com muita agonia, reconhecendo a dificuldade em retomar a respiração, o ritmo, a coordenação e o raciocínio após esse tipo de episódio. Da mesma forma que há necessidade do esforço vocal intenso, há, logo a seguir, a necessidade de ajustes na respiração e na voz, para retomar a calma e o ensino. Tudo isso ocorre muito rápido, pois precisam dominar a sala e continuar a aula, de algum modo.

Um aspecto que se destacou - pois intensifica a necessidade de fala em condições estressantes e, muitas vezes, contínuas em classes indisciplinadas - foi a impossibilidade de organização da rotina dos professores, por causa das constantes interrupções pela necessidade de reprimendas, interferência em brigas, orientação em situação de bullying, trabalho em situações decorrentes da inclusão escolar, dentre outras ocorrências.

Devido ao fato de terem que usar a voz continuamente e com sobreposição de intenções e ajustes vocais, como por exemplo, dar aula e chamar a atenção de um aluno, controlar a turma e acudir alguém, as professoras sentem-se impotentes diante das adversidades provenientes das precárias condições e da forma como se dá a organização do trabalho. Ficam sobrecarregadas não só de tarefas, mas de responsabilidades, como restabelecer a ordem, a segurança e o direito das crianças diante de uma instituição que não provê o necessário.

Constatou-se que há falta de funcionários nas escolas, incluindo professores, gerando uma série de situações administrativas e organizacionais, que fazem com que os docentes se sintam responsáveis por seus alunos e por tudo o que se relaciona a eles: progressos ou insucessos, bons ou maus comportamentos, acidentes, ter aula ou não ter, dentre outros aspectos.

As dificuldades relatadas pelas professoras da presente pesquisa, no que diz respeito a se ausentarem da sala de aula para tratamento, parecem estar diretamente relacionadas a esse sentimento de responsabilidade. Muitas vezes, trabalharam sem voz para não faltarem, preocupadas com seus alunos. Observouse, em suas falas, um sentimento de culpa por se ausentarem da escola, aparentemente sentindo-se em falta com seus alunos, com os pais desses alunos e com a escola.

Notou-se que há no ambiente escolar uma naturalização do adoecimento vocal dos professores, afinal todo professor acaba ficando rouco por um dia, por dois dias, por uma semana e assim progressivamente.

As professoras comentaram sobre a existência de muitas pessoas nas escolas com problemas de voz e que nunca se trataram. Outras, que se trataram e melhoraram, voltaram a trabalhar, adoeceram novamente e não quiseram mais fazer tratamento. Algumas com vozes péssimas, segundo elas, mas há o receio de irem ao médico e serem readaptadas em suas funções. A readaptação é condição de grande desprestígio e sofrimento para as professoras.

As participantes dos grupos focais contempladas neste estudo trabalhavam há muitos anos na prefeitura de São Paulo e já haviam trabalhado em várias escolas. Portanto, quando falaram sobre condições e organização do trabalho, referiam-se a locais que abrangiam bem mais do que as escolas em que se encontravam no momento.

Ao falarem sobre a estrutura física, material e de recursos humanos das escolas, expuseram, ao mesmo tempo, o sentimento de abandono e desespero que sentem em seus locais de trabalho. 
Mencionaram, também, que percebem que a falta de funcionários, de pessoal de apoio e de professores interfere significativamente no funcionamento das escolas, nas relações entre as pessoas do ambiente escolar e com a comunidade, atingindo, fundamentalmente, o trabalho docente.

Referiram que, mediante eventos inesperados, ou quando há sobreposição de tarefas, ou seja, em situação de urgência, a resposta é a que for mais rápida. Essa condição é desfavorável ao desenvolvimento de estratégias de proteção à própria saúde, como por exemplo, evitar o abuso vocal.

A emoção aflorou em vários depoimentos, como se as professoras estivessem, ainda, portando aqueles sentimentos e sensações vividos em momentos de forte intensidade afetiva. Algumas vezes, em seus discursos, tinha-se impressão de que não existia fronteira, delimitação para o trabalho dos docentes.

Apesar de todos os esforços despendidos para dar conta de suas múltiplas incumbências, a desvalorização da profissão por parte da sociedade, da direção das escolas, dos pais e dos alunos, levam a situações de desrespeito, ameaças ao professor por parte dos pais, agressões físicas, verbais e de toda ordem.

As professoras desta investigação desenvolveram várias estratégias para lidar com as situações do seu cotidiano como, por exemplo, "saber falar com os pais mais agressivos"; "saber quando interromper a conversa antes de ser agredida"; segurar pela blusa, à distância, para não apanhar ao separar brigas; ignorar certas atitudes provocativas, entre outras.

Em todas as situações, a responsabilidade sempre recai sobre o professor, seja porque não orientou antes e deveria tê-lo feito, seja porque não interferiu a tempo, seja porque não teve uma atitude firme.

O sentimento de culpa nos pareceu enraizado nas professoras participantes. Seus discursos revelaram um estado de constante atenção, como se o tempo todo estivessem em alerta, aguardando o inusitado e devessem estar aptas, a qualquer momento, para restabelecer a ordem.

A inclusão escolar foi assunto frequente nos grupos, quando o tema era a violência. Foi possível perceber que desperta sentimentos ambíguos nessas professoras. Ao mesmo tempo que aceitam como um desafio, uma possibilidade de crescimento, são prejudicadas pela falta de recursos de toda ordem. Não há cursos, não há auxiliares, não há preparo dos espaços físicos em várias escolas e, mais uma vez, elas têm que absorver e dar conta da assistência/educação dessas crianças.

Foram vários os depoimentos e a impressão foi de que a inclusão escolar, da forma como está estabelecida, é vivenciada como uma violência às professoras e ao seu trabalho, gerando sofrimento intenso, sobrecarga, medo e angústia, decorrentes de comportamentos com os quais não estão preparadas para lidar, não escolheram, não foram consultadas e nem lhes foi dada a condição de decisão. Sendo assim, constatou-se que as professoras pesquisadas precisam se reinventar dia a dia, buscando exercer o seu ofício em um tênue equilíbrio entre a saúde e o adoecimento, incluindo os distúrbios da voz.

\section{DISCUSSÃO}

As participantes desta pesquisa relataram o uso intenso da voz, "o gritar", "o falar" em forte intensidade como: recurso a longo prazo, para garantir o aprendizado; recurso a médio prazo, para trabalhar procedimentos e atitudes que desejam mudar, como a indisciplina, o bullying, preconceitos, atitudes agressivas, dentre outros e recurso a curto prazo, para dar conta de situações que exigem um controle imediato, uma interferência premente, como brigas ou situações de perigo.

Em estudo de $2010^{(13)}$, numa análise de regressão múltipla, foi encontrada associação entre rouquidão e ausência de ingestão de água, gritar/falar alto, pouca abertura mandibular e dormir, em média, seis horas por noite. Constataram, ainda, associação entre fadiga vocal e gritar/falar alto, falar excessivamente, dificuldade em abrir a boca para mastigar, dormir menos de seis horas por noite.

A quantidade de fala e a intensidade vocal elevada estão relacionadas a lesões benignas de mucosa, como pólipos, nódulos, ectasias e hemorragias que, usualmente, são encontradas em profissionais da voz. É importante compreender como esses dois aspectos se relacionam no uso profissional da voz e no uso cotidiano, considerando as variações individuais. Nos estudos com profissionais da voz, foi observado maior uso de fala e maior intensidade de voz no uso laboral, em comparação com o extralaboral ${ }^{(14)}$.

Professores de Ensino Infantil e de Ensino Fundamental têm um envolvimento maior com os alunos, falam alto, resultando em aumento excessivo da tensão da musculatura do pescoço e em maior número de sintomas vocais e de risco para o distúrbio de voz ${ }^{(15)}$.

Um estudo sobre a hipersolicitação vocal - um conjunto de estratégias com ajustes vocais específicos, como prolongamento do uso da voz, mudanças na qualidade vocal habitual, repetições e voz cantada - mostrou que são um conjunto de comportamentos vocais deletérios, potencialmente relacionados ao adoecimento e recidiva do quadro de distúrbio de voz, embora sejam considerados recursos didáticos ${ }^{(16)}$, associados à compreensão e reforço de conteúdos, controle da disciplina, transmissão e fixação de conteúdos, dentre outros recursos na sala de aula.

A sala de aula sofre interferências múltiplas e complexas, caracterizada por "multidimensionalidade, simultaneidade de eventos, imprevisibilidade, imediaticidade e unicidade" (p.64) ${ }^{(17)}$, exigindo do professor, na tomada de decisões, que enfrentem exigências e interesses que competem entre si. É um processo dinâmico, que requer um ponto de equilíbrio entre múltiplos custos e benefícios, pois, em geral, o professor tem que responder imediatamente às situações.

Estudos indicaram maior prevalência de rouquidão em professores com menos de 15 anos de docência e o número de alunos em sala de aula mostrou-se como potencial fator de risco à saúde vocal ${ }^{(18)}$. 
Nas escolas, são encontrados níveis de ruído acima do limiar de conforto acústico estabelecido pelas normas e acima do limite de tolerância ${ }^{(19)}$ e sabe-se que o professor compete vocalmente para superar o ruído, fazendo esforço intenso para se fazer ouvir. O impacto do ruído ambiental na voz dos professores, numa demanda contínua, pode gerar desgaste, produzindo distúrbio vocal, mas não foi possível estabelecer correlação entre a excessiva ocorrência de vozes alteradas e o nível de ruído ambiental ${ }^{(20)}$.

Estudiosos analisaram que, em sala de aula, os professores, após várias tentativas de separar brigas de alunos e estabelecer o clima necessário para o ensino, parecem desistir e se "desligar", ignorando a indisciplina: "o aparente desligamento seria uma manifestação de sofrimento diante de uma situação que requereu à exaustão a sua energia" (21).

A intensificação do trabalho exige do trabalhador a execução simultânea de múltiplas tarefas que concorrem entre si e interferem na atividade principal $^{(22)}$.

Quanto a se ausentarem do trabalho para tratamento, os professores são relutantes, pois, talvez, tenham medo que o médico sugira procedimentos, com recomendações para a redução do uso da voz no trabalho, ou para parar completamente de trabalhar ou, ainda, para mudar de ocupação ${ }^{(23)}$.

A voz é um instrumento poderoso do educador. Sem ela, seu trabalho fica truncado, limitado ou até impedido, sem contar que a voz, por meio de sua inflexão, fornece brilho, cor, dá vida às emissões. Parece ilógico conceber que um professor possa trabalhar sem voz dentro da sala de aula, com seus alunos - discurso corrente entre os professores - reforçado pelas dificuldades e todo tipo de empecilho para que se ausentem da escola.

Alterações vocais como rouquidão, falhas na voz, afonia e dificuldade para falar em forte intensidade interferem na satisfação dos professores, em seu desempenho e em sua assiduidade, sendo causa de $20 \%$ das faltas ao trabalho ${ }^{(23)}$.

O indivíduo é representado pelo som da sua voz em suas características físicas, emocionais e socioculturais. Nesse sentido, nas situações de comunicação interpessoal, as várias emoções e sentimentos, como medo, frustrações, inseguranças, tensões, estados de alerta constante, raiva, necessidade de controle e sensação de impotência, que foram relatados pelas participantes dos grupos focais, estão presentes nas relações comunicativas que se estabelecem na escola.

Uma investigação sobre a voz de professores do Ensino Infantil e Fundamental e condições psicossociais do trabalho, realizada em 2010, na Espanha, com 282 sujeitos, identificou que indivíduos do grupo com distúrbio de voz foram expostos a piores condições psicossociais, em relação aos que não apresentavam distúrbio de voz ${ }^{(15)}$.

Nesse estudo, de 21 das dimensões estudadas, o grupo com distúrbio de voz estava afetado em 20 delas: prestar atenção constante no trabalho; exigência de esconder as emoções; não levar problemas para casa; perceber o trabalho como emocionalmente desgastante; sentir as situações como emocionalmente exaustivas; não poder deixar o local de trabalho momentaneamente; não ter influência sobre o trabalho - não opinar; ter tarefas ambíguas ou contraditórias; não saber exatamente seu papel no trabalho; não ter previsibilidade no trabalho; não contar com colegas para ouvi-los; não contar com supervisores para ouvi-los; não perceber o auxílio de supervisores; julgar que os supervisores nunca resolvem problemas apropriadamente; não ter evolução salarial; não sentir-se reconhecido pela direção e não ter acolhimento em situações controversas ${ }^{(15)}$. Ressalta-se que essas condições adversas também foram relatadas pelas professoras da presente pesquisa.

Os professores com distúrbio de voz têm insatisfação em dobro com o trabalho e com as condições do ambiente de trabalho em relação aos que não apresentam distúrbio de voz ${ }^{(15)}$.

A educação tem sofrido as consequências da nova regulação de políticas educacionais na América Latina, que reestruturou o trabalho docente por meio de mudanças significativas na gestão escolar e nas condições em que o ensino se dá, evidenciadas pela centralidade atribuída à administração escolar nos programas de reforma, em que a escola é vista como núcleo do planejamento e da gestão; pelo financiamento per capita; pela regularidade e ampliação dos exames nacionais; pela avaliação institucional e pelos mecanismos de gestão escolares, com a participação da comunidade. Pressupôs, ainda, adequações, segundo critérios de produtividade, eficácia e excelência. Interferiu nas relações de trabalho na escola e nos procedimentos de evolução na carreira e na remuneração do docente ${ }^{(24)}$.

A Conferência Mundial sobre Educação para Todos, em 1990, propôs, como orientação para os países mais pobres e populosos do mundo, a educação para a equidade social, que resultou em criar estratégias de aumento do nível de atendimento às populações, porém, com pouco investimento ${ }^{(25)}$. Como consequência à contenção dos gastos com a educação pública, houve precarização do ensino fundamental ${ }^{(26)}$.

Nessa reforma, duas orientações são indispensáveis: descentralização financeira e descentralização pedagógica. Esta última, resulta na elaboração coletiva do projeto pedagógico pelo estabelecimento de ensino. Do ponto de vista do trabalho docente, acarretou sobrecarga, pela reestruturação do trabalho pedagógico, ocasionando maior responsabilização dos professores e maior envolvimento da comunidade ${ }^{(25-27)}$.

Cria-se a ilusão de que é preciso reformar a educação e atribui-se ao professor um papel determinante no alcance da qualidade do ensino público, responsabilizando-o pela quantidade infindável dos problemas educacionais e, por fim, condenando-o pelas precárias condições do ensino público com que nos defrontamos de forma particularmente drástica nos países pobres ${ }^{(26)}$.

Os professores são "considerados os principais responsáveis pelo desempenho dos alunos, da escola e do sistema", e que, frente às variadas funções que a escola assume, "encontram-se frequentemente diante da necessidade de responder às exigências que estão além de sua formação" (24,27). 
Assim, é possível entender os discursos das professoras participantes da presente pesquisa, quando alegaram que "tudo é o professor" dentro da escola, que ele mal chega e já está trabalhando, que parece que a escola só funciona por conta dos professores, que têm dificuldade em se ausentar, pela falta de funcionários - por não haver quantidade suficiente e muito adoecimento - e que a inclusão social sem nenhuma preparação não é factível nesse contexto.

A discussão dos baixos salários dos professores como tendência mundial geral de precarização do emprego, também deve ser considerada ${ }^{(25)}$. Como evidências da precarização do trabalho docente - além dos baixos salários - há o alto número de alunos por professor em todos os níveis de escolarização, pois aumenta a taxa de exploração do trabalho docente, tendo em vista a intensificação do trabalho a ser realizado no mesmo período de tempo ${ }^{(27)}$; ínfimos investimentos nos diferentes níveis de educação; perda de direitos; recursos financeiros destinados às escolas e aos professores atrelados a resultados obtidos na avaliação de seus alunos ${ }^{(25)}$.

É possível avaliar a precarização do trabalho pela saúde dos trabalhadores e, em estudos sobre a América Latina, esse é um denominador comum $^{(24,25)}$.

Há uma série de situações que, disfarçadas no bojo da nova postura da escola frente à comunidade, trazem consigo sentimentos de desprofissionalização e de perda de identidade profissional ao educador, que se vê assumindo funções que o desqualificam, como por exemplo, organizar gincanas esportivas, suprir necessidade de lazer da região onde se situa a escola, dentre outras ${ }^{(28)}$.

A gestão da escola - nova atribuição aos professores ${ }^{(24-28)}$ está longe de ser a democratização da organização do trabalho e se restringe a uma sobrecarga de trabalho ${ }^{(25,27)}$, na medida em que os docentes não possuem autonomia e nem interferem na concepção e na organização do trabalho(28).

Conclui-se que "Polivalência, voluntarismo, desprofissionalização, desqualificação, apelo à criatividade em contexto de precariedade, essas palavras remetem a um fenômeno que não é exclusivo da educação. Isso revela que, apesar de o trabalho docente não poder ser submetido de modo real à organização do trabalho capitalista, as mudanças ocorridas no trabalho em geral (trabalho produtivo) repercutem na atividade do professor. [...] estando em curso uma verdadeira reestruturação do trabalho da categoria, cuja marca principal é a precarização do trabalho e das relações de emprego no magistério [...]"(28).

Observou-se, em várias situações descritas nos grupos focais, que "os professores se sentem obrigados a desempenhar funções que estão para além de suas capacidades técnicas e humanas [...] os professores são constrangidos a buscar respostas para essas demandas" (p.213) ${ }^{(28)}$.

A intensificação do trabalho assume características próprias da realidade latino-americana atual, a saber: ampliação da jornada de trabalho dentro da escola em que trabalha; aumento considerável de responsabilidades; assumir mais de uma jornada; não encontrar tempo para atualizar-se, para preparar aulas; levar trabalho para casa; responder a exigências da comunidade; se sentir forçado a dominar novas práticas, novos saberes e novas competências, tomando-os como novidades naturais e indispensáveis ${ }^{(28,29)}$, caracterizando, porém, dessa forma, a perda de autonomia e do controle do trabalhador/ professor sobre seu processo de trabalho ${ }^{(29)}$.

A reforma que ocorreu na educação e suas consequências, apresentadas aqui, de forma resumida, foram nomeadas por uma das professoras da pesquisa e acatadas pelas demais, como uma violência silenciosa, que, nos seus dizeres, são todos os comportamentos e solicitações dirigidos aos professores por parte da sociedade, dos alunos, dos pais de alunos, dos funcionários e da administração das escolas e que os despersonificam e os desqualificam ${ }^{(28,29)}$ em suas funções como educadores.

Em suas falas, as professoras manifestaram todos os aspectos expostos anteriormente em discursos muito claros, fazendo nomeações de diversas situações como opressoras, restritivas, invasivas e muito angustiantes.

Houve uma dilatação no plano legal do que seja o pleno exercício da docência, à medida que o trabalho do professor não se restringe à sala de aula, mas se estende à comunidade, à gestão da escola, ao planejamento pedagógico, dentre outras funções. Essas atribuições promovem efeitos deletérios à saúde dos docentes, pois esse modelo de massificação da educação, desregulação e redefinição de tarefas, faz com que se perca a noção do que seja um "bom trabalho"(27).

Há contradições entre a assistência global à criança versus a ausência de meios, pois esse processo exige do docente intensificação do seu trabalho, mobilizando recurso extra para estar atento a duas tarefas concorrentes ${ }^{(28)}$. Há, também, o desenvolvimento de habilidades relacionais para lidar com pais, alunos, comunidade e para mediar situações de violência nas escolas e as que adentram as escolas ${ }^{(27)}$.

Sobreposição de tarefas, hipersolicitação do corpo - incluindo aqui o distúrbio de $v Z^{(21)}$ - exposição a várias fontes de ruído, não ter controle sobre o próprio trabalho ${ }^{(29)}$, realizar, contrariada, tarefas que requerem esforços, carga de trabalho redobrada - relembrando que, concomitantemente, o número de professores efetivo diminuiu - são alguns dos indicadores do processo de intensificação do trabalho e de riscos à saúde física e mental ${ }^{(27)}$.

\section{CONCLUSÃO}

A nova regulação das políticas educacionais reestruturou o trabalho docente, acarretando sobrecarga e intensificação do trabalho do professor, precarizando as condições laborais e interferindo na sua organização. O professor é solicitado, cotidianamente, a um uso intenso da voz para resolver várias situações, além de ministrar a aula, sem possibilidade de repouso vocal e em condições adversas, que provocam o adoecimento de seu corpo e de sua mente. 


\section{REFERÊNCIAS}

1. Vilela FCA, Ferreira LP. Voz na clínica fonoaudiológica: grupo terapêutico como possibilidade. Disturb Comun. 2006;18(2):235-43.

2. Giannini SPP, Passos MC. Histórias que fazem sentidos: as determinações das alterações vocais do professor. Disturb Comun. 2006;18(2): 245-57.

3. Ferreira LP, Giannini SPP, Figueira S, Silva EE, Karmann DF, Thomé-de-Souza TM. Condições de produção vocal de professores da rede do município de São Paulo. Disturb Comun. 2003;14(2):275308.

4. Delcor NS, Araújo TM, Reis EJFB, Porto LA, Carvalho FM, Silva MO, et al. Condições de trabalho e saúde dos professores da rede particular de ensino de Vitória da Conquista, Bahia, Brasil. Cad de Saúde Pública. 2004;20(1):187-96.

5. Araújo TM, Sena IP, Viana MA, Araújo Em. Mal-estar docente: avaliação de condições de trabalho e saúde em uma instituição de ensino superior. Rev Baiana de Saúde Pública. 2005;29(1):06-21.

6. Gasparini SM, Barreto SM, Assunção AA. O professor, as condições de trabalho e os efeitos sobre sua saúde. Educação e Pesquisa. 2005;31(2):189-99.

7. Medeiros AM, Barreto SM, Assunção AA. Voice disorder (dysphonia) in public school female teachers working in Belo Horizonte: prevalence and associated factors. J Voice. 2008;22(6):676-87.

8. Vilkman E. Occupational safety and health aspects of voice and speech professions. Folia Phoniatr Logop. 2004;56(4):220-53.

9. Carneiro SAM. Saúde do trabalhador público: questão para a gestão de pessoas - a experiência na Prefeitura de São Paulo. Rev do Serviço Público (Brasília). 2006;57(1):23-49.

10. Leite MP, Souza AN. (Coord.). Condições do trabalho e suas repercussões na saúde dos professores da educação básica no Brasil - Estado da Arte. Campinas: Universidade Estadual de Campinas; 2007.

11. Dragone MLS, Ferreira LP, Giannini SPP, Simões-Zenari M, Vieira VL, Behlau M. Voz do professor: uma revisão de 15 anos de contribuição fonoaudiológica. Rev Soc Bras Fonoaudiol. 2010;15(2):289-96.

12. Barbour R. Grupos focais. Porto Alegre: Artmed; 2009.

13. Ferreira LP, Latorre MRDO, Giannini SPP, Ghirardi CAM, Karmann DF, Silva EE, et al. Influence of abusive vocal habits, hydration, mastication and sleep in the occurrence of vocal symptoms in teachers. J Voice. 2010;24(1):86-92.

14. Padilha MP, Moreti F, Raize T, Sauda C, Lourenço L, Oliveira G, Behlau M. Grau de quantidade de fala e intensidade vocal de teleoperadores em ambiente laboral e extralaboral. Rev Soc Bras Fonoaudiol. 2012;17(4):385-90.
15. Bermúdez de Alvear RM, Martínez-Arquero G, Barón FJ, Hernández-Mendo A. An interdisciplinar approach to teachers'voice disorders and psychosocial working conditions. Folia Phoniatr Logop. 2010;62(1-2):24-34.

16. Vianello L, Assunção AA, Gama ACC. Estratégias implementadas para enfrentar as exigências vocais da sala de aula: o caso das professoras readaptadas por disfonia. Disturb Comun. 2008;20(2):163-70.

17. Reali AMMR, Mizukami MGN (Org.) Formação de professores: tendências atuais. São Carlos: EDFSCar; 2007.

18. Palheta Neto FX, Rebelo Neto OB, Ferreira Filho JSS, Palheta ACP, Rodrigues LG, Silva FA. Relação entre as condições de trabalho e a autoavaliação em professores do ensino fundamental. Arq Int Otorrinolaringol. 2008;12(2):230-38.

19. Batista JBV, Carlotto MS, Coutinho AS, Pereira DAM, Augusto LGS. O ambiente que adoece: condições ambientais de trabalho do professor do ensino fundamental. Cad Saúde Colet. (Rio de Janeiro). 2010;18(2):234-42.

20. Guidini RF, Bertoncello F, Zanchetta S, Dragone, MLS. Correlações entre ruído ambiental em sala de aula e voz do professor. Rev Soc Bras Fonoaudiol. 2012;17(4):398-404.

21. Noronha MMB, Assunção AA, Oliveira DA. O sofrimento no trabalho docente: o caso das professoras da rede pública de Montes Claros, Minas Gerais. Trabalho, Educação e Saúde (Rio de Janeiro). 2008;6(1):65-86.

22. Ferreira MC. Interação teleatendente-teleusuário e custo humano do trabalho em central de teleatendimento. Rev Bras Saúde Ocup. 2004;29(110):7-15.

23. Roy N, Merrill RM, Thibeault S, Parsa RA, Gray SD, Smith EM. Prevalence of voice disorders in teachers and the general population. J Speech Lang Hear Res. 2004;47:281-93.

24. Oliveira, DA. Regulação educativa na América Latina: repercussões sobre a identidade dos trabalhadores docentes. Educação em Revista (Belo Horizonte). 2006;44:209-27.

25. Oliveira CB, Gonçalves GBB. Precarização do trabalho docente na Argentina, Colômbia e Brasil: um estudo comparado. Revista Digital (Buenos Aires). 2008;13(119).

26. Rabelo J, Mendes Segundo MD, Jimenez S. Educação para todos e reprodução do capital. Trabalho Necessário. 2009;7(9):1-24.

27. Assunção AA, Oliveira DA. Intensificação do trabalho e saúde dos professores. Educ Soc. 2009;30(107):349-72.

28. Paparelli R. Desgaste mental do professor da rede pública de ensino: trabalho sem sentido sob a política de regularização de fluxo escolar [tese]. São Paulo: Universidade de São Paulo; 2009.

29. Oliveira DA. A reestruturação do trabalho docente: precarização e flexibilização. Educ Soc. 2004;25(89):1127-44. 